\title{
THERMAL ANALYSIS OF BRAKE DISC
}

\author{
Swapnil.D.Kulkarni ${ }^{1}$, J.J.Salunke ${ }^{2}$ \\ ${ }^{I}$ ME Student, Mechanical Engineering Department, DIEMS, Maharashtra, India. \\ ${ }^{2}$ Assistant professor, Mechanical Engineering Department, DIEMS, Maharashtra, India.
}

\begin{abstract}
In today's developing automobile sector, there is drastic change in the technology from transmission system to braking system. The braking system is considered as one of the most important system from performance as well as safety point of view. When the brakes are applied to the moving vehicle, all the kinetic energy of the vehicle get converted into equivalent amount of heat generation. Disc brake is the recent trend in automobile vehicles which dissipates the heat faster than the conventional drum brakes. but if hard braking is done, there is induction of thermal stresses in the brake disc which leads to generation of excessive temperature if this heat is not dissipated properly, then distortion will be get produced in the disc which leads to thermal cracking of the disc leading to disc failure. The brake disc has an inherent ability that there is no change of co-efficient of friction on the disc so there is no problem of brake fading phenomenon. The main advantage of disc brake is that only a small portion of the disc is in contact with the friction material i.e. the caliper. Hence there is large surface area of the disc which can dissipate the heat to the atmosphere. Specifically the heat dissipated to the atmosphere is the forced convection mode. The aim of this research work is to choose best profile and best material which can dissipate maximum amount of heat to the surrounding. The models of disc are created in Creo parametric 2.0while the analysis is conducted in ANSYS 15.0.the analysis performed in ANSYS is steady state thermal.
\end{abstract}

Keywords: Thermal Analysis, Disc Brake, ANSYS,

\section{INTRODUCTION}

Disc brake is one of the types of brake which uses calipers to push the stationary pads to hold the rotating disc produce a friction. The retardation of the vehicle is obtained by applying the pressure on the disc \& caliper assembly which is attached to the wheel or axle.There is conversion of the kinetic energy of the vehicle to the heat energy which is then dissipated to the surrounding in the form of heat. [1].

A brake is a contact mechanical device for changing over the momentum or kinetic energy of the moving vehicle into heat by method for rubbing. It is obliged to stop or ease off the vehicle in the briefest conceivable separation when needed to do so. [2]

When hydraulic pressure is applied to the caliper piston, the pressure tends to exert a force on the caliper which results in squeezing the disc between two friction surfaces of the disc. Since disc brakes do not use friction between the lining and rotor to increase braking power as drum brakes do, they are less likely to cause a pull. As most of the portion of the disc brake is exposed to the surrounding, there is best heat dissipation rate which gives faster cooling of the disc brake disc. This phenomenon plays an important role in minimizing the brake fade. It also allows for self-cleaning as dust and water is thrown off, reducing friction difference. [3]

\section{LITERATURE REVIEW}

According to PraveenaS Lavakumar, cast iron is suggested as the best material for the brake disc as it has low thermal conductivity.[4]
Venkatkumar R gurubaran in their "design and analysis of disc brake rotor stated that copper liners can be also used for making the brake disc rotor as it gives moderate cooling at low temperatures.[5]

Ganesh P and Naresh C in "Finite element analysis of normal and vented disc rotor" stated that "Aluminum metal matrix is more beneficial for use as it is lighter in weight, better wear resistant and thermal conductivity". They also come to conclusion that "Aluminum utilization for brake disc manufacturing can contribute to increase in acceleration and reduction in braking distance". [6]

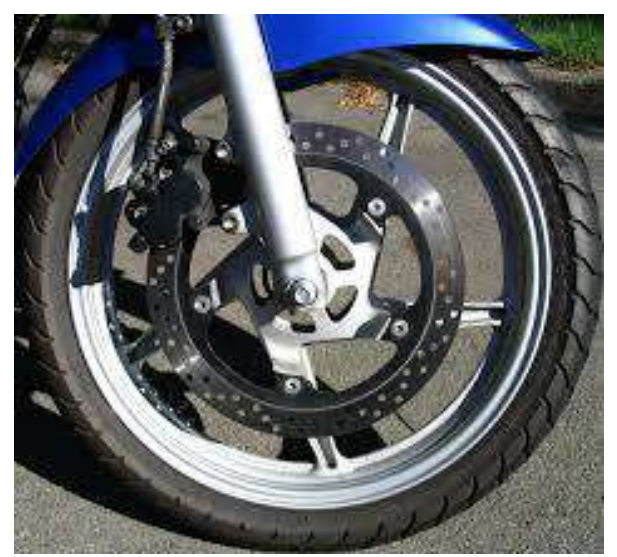

Fig -1: Disc brake assembly mounted on front wheel.

Hemraj nimhal et al. in their "Thermal analysis of disc brake using ANSYS software" stated that "use of non vented disc made up of ceramic material can be prove as best material for future because of its Mechanical and material properties.[7] 
Bhaskarasetupathi et al.in their "Numerical analysis of rotor disc for optimization of disc material" stated that Aluminum metal matrix is suitable for the manufacturing of the disc brake in mechanical strength and thermal strength with the condition that the tribological characteristics should be suitable.[8]

Subhasissarkar and Dr.PravinRathod in "modeling and simulation of disc brake to analyze the temperature distribution using FEA" stated that "Increase in vehicle speed, the temperature increases but the rate of heat generation with speed is less for AMMC as compared with Grey Cast iron. They also come to conclusion that "disc brake design plays an important role in heat transfer like vent hole size, vane thickness etc. [9]

A. Belhocineet al. in "Thermal analysis of both ventilated and full brake disc rotors with frictional heat generation" concluded that the radial ventilation plays a vital important role in the cooling of the disc during the braking phase. [10]

\section{CALCULATION FOR HEAT FLUX}

In the experimental investigation conducted on the disc brake, we have prepared 3 different profiles and the profiles were made up of three different materials namely stainless steel 410, Cast iron and aluminum. the boundary condition is that the vehicle has a loaded weight of $300 \mathrm{~kg}$ and it runs with a maximum speed of $100 \mathrm{Kmph}$.

- Mass of the vehicle: $100 \mathrm{~kg}$.

- Maximum speed of vehicle: $100 \mathrm{kmph}$

- Kinetic energy of the vehicle $: 0.5 \mathrm{mv}^{2}$

- Rotor disc diameter in meter:0.241m

- Permissible temperature in Celsius: $250^{\circ} \mathrm{C}$.

- Pressure applied on the brake pads: $1 \mathrm{Mpa}$.

- Tangential force acting on the disc:2835.20 N.

- Stopping distance for the vehicle: 40.823 meters.

- Generated heat flux for above condition for stainless steel 410: $23148.14 \mathrm{watt} / \mathrm{m}^{2}$.

- Heat flux for disc profile made up of cast iron: $16724 \mathrm{watt} / \mathrm{m}^{2}$.

- Heat flux for profile III: $11342 \mathrm{watt} / \mathrm{m}^{2}$.

The calculation for the heat flux is done by the relations given in the brake design and safety by Rudolf Limpert.

All the heat flux values are applied to the models in ANSYS 15.0. The models are created in Creo parametric 2.0 while the analysis is performed in ANSYS.15.0.

\section{METHODOLOGY}

The experimental setup for the thermal analysis of brake disc consists of a bed on which an alternating current induction motor of $3 \mathrm{HP} 3000 \mathrm{rpm}$. The disc is allowed to reach the desired speed and the brake is applied by the help of brake lever. The temperature of the disc is measured by the temperature sensor and temperature sensing gun. After completely stopping the disc, again the disc is rotated by the motor till it achieves the desired speed and again the action is repeated.
The temperature sensors used for our experimentation is non- contact type infra-red temperature sensor/temperature sensing gun.

The Analysis in ANSYS is carried by following method.

- First of all the profiles are created in Creo parametric 2.0.

- After starting ANSYS 15.0, the mode of analysis is taken as steady state thermal.

- The material properties are defined for the profile models.

- The model is then subjected to meshing where the relevance or the meshing is defined.i.e. Fine meshing or coarse meshing.

- After meshing, the boundary conditions are applied to the brake disc.

- The parameters whose solution is required are selected from the solution bar.

- The results are obtained in the form of contour images and the result is compared with the actual value obtained by the experimentation.

Following are the profiles of the brake disc used for the analysis purpose.

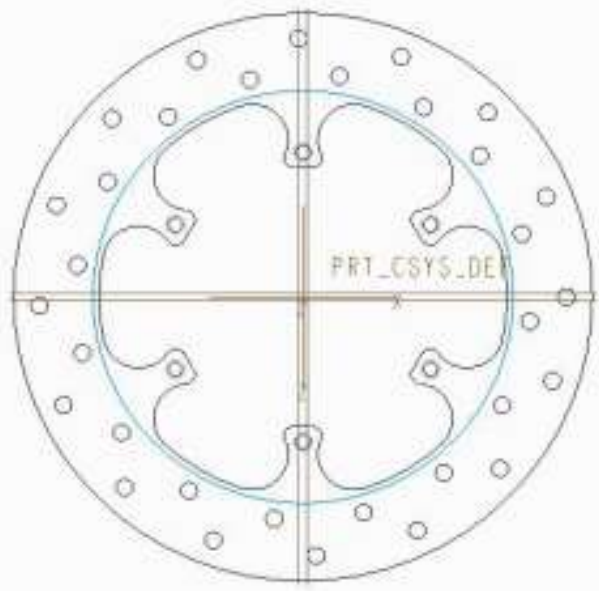

Fig-2: Profile I.

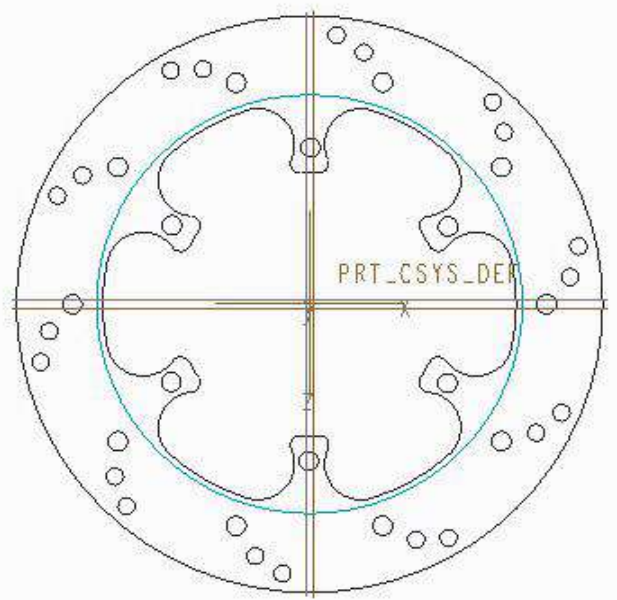

Fig-3: Profile II. 


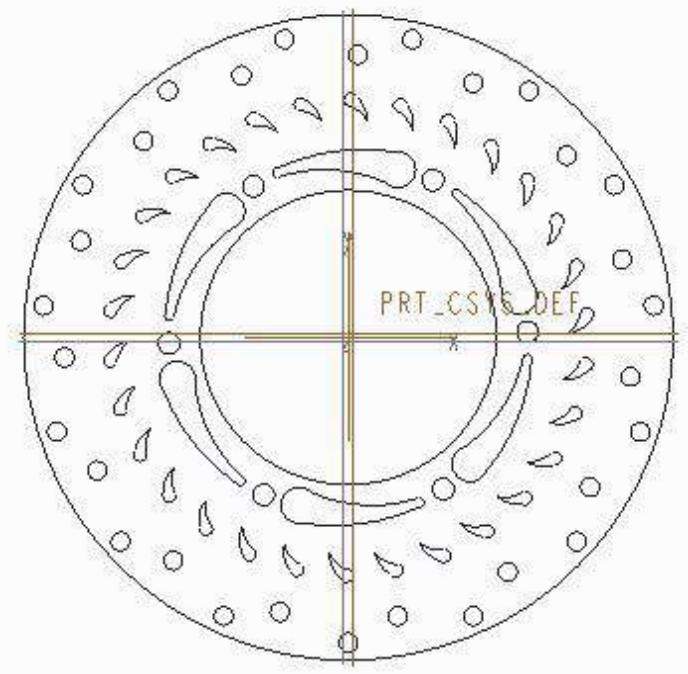

Fig-4: Profile III.

The models are analyzed for steady state thermal analysis for three different materials. i.e. Stainless steel DB410, Cast iron and Aluminum.

After meshing, the profile model gets discretized into small fragments which are called as nodes. Thusthe boundary conditions get applied to every node. The meshing details of the profile are given below.

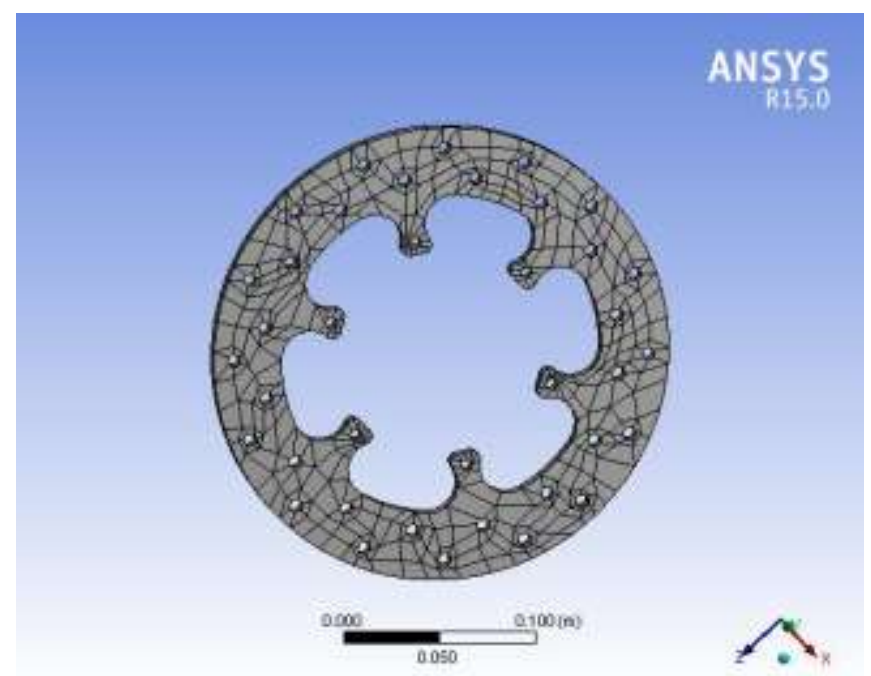

Fig-5: Meshing details for profile I.

All the profiles are meshed for the further investigation of the heat dissipation through the brake disc. The meshing relevance for our analysis is that we have selected the relevance size as coarse grid size or we can say the meshing is in the coarse structure form.

In the same manner meshing is performed for the profile II and III. The meshing details for all the three materials i.e. stainless steel DB410, Cast iron and Aluminum are performed in the same manner like previous one

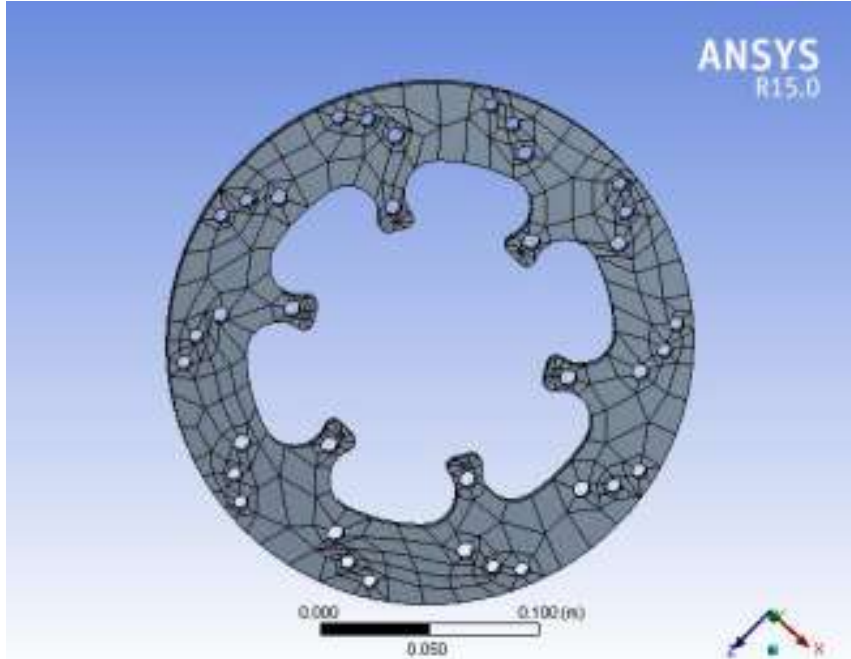

Fig-6: Meshing details for profile II.

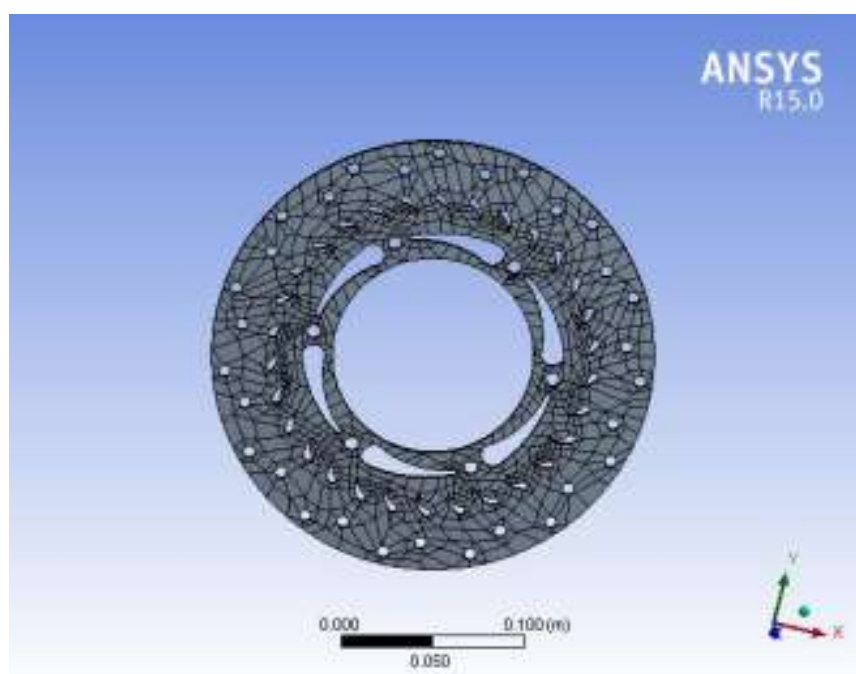

Fig-7: Meshing details for profile III.

\section{RESULT AND DISCUSSION}

The result obtained by the actual experimentation and the analysis is checked and the results are interpreted as below .In ANSYS, the two main solutions are calculated the first one is the temperature and the other is the heat flux. The results obtained by ANSYS are reviewed firstly.

The contour diagrams for the profiles are given as follows. The results obtained by the software are verified by the experimental values which are get obtained by the experimental work.the main advantage of the software analysis is that it discretizes the whole model into a small sized fragments. The boundary conditions are first get applied to the nodes and then the final solution is achieved by the addition of individual node. Thus, the results obtained by the software are more precise than the experimental value. There will be some difference in the experimental value and the software value. 


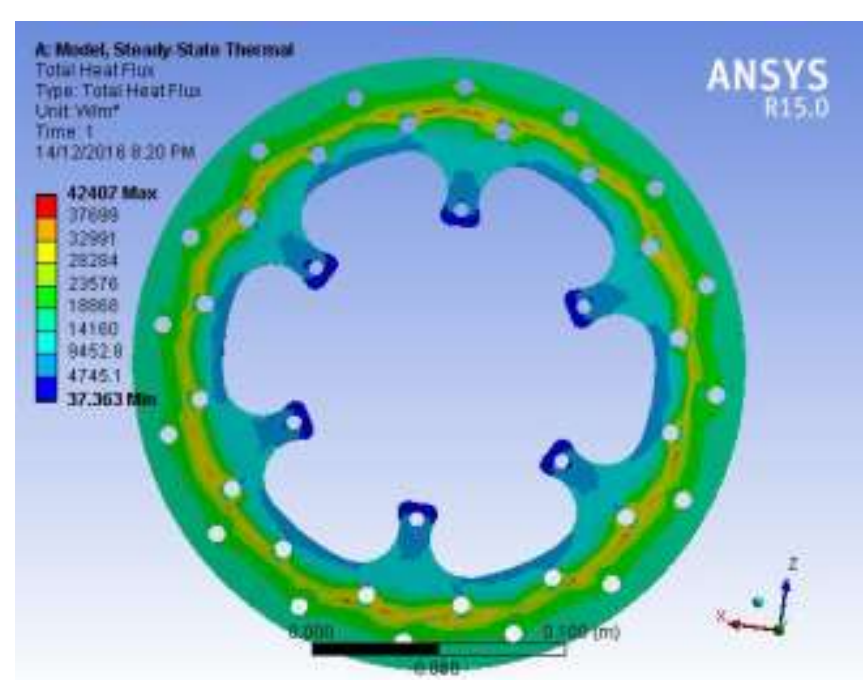

Fig-8: Total heat flux for profile I DB410.

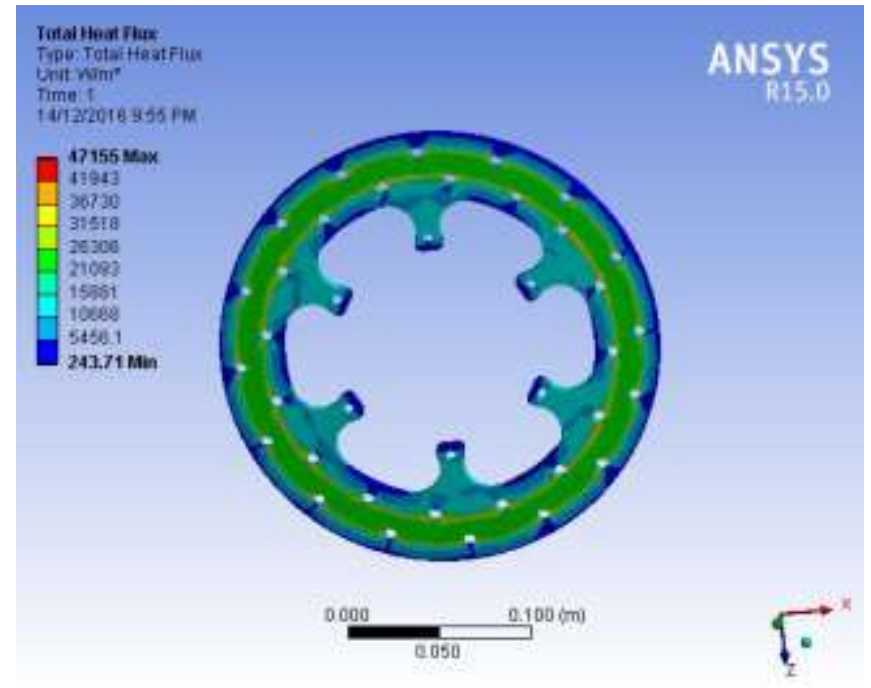

Fig-9: Total heat flux for profile I Cast iron.

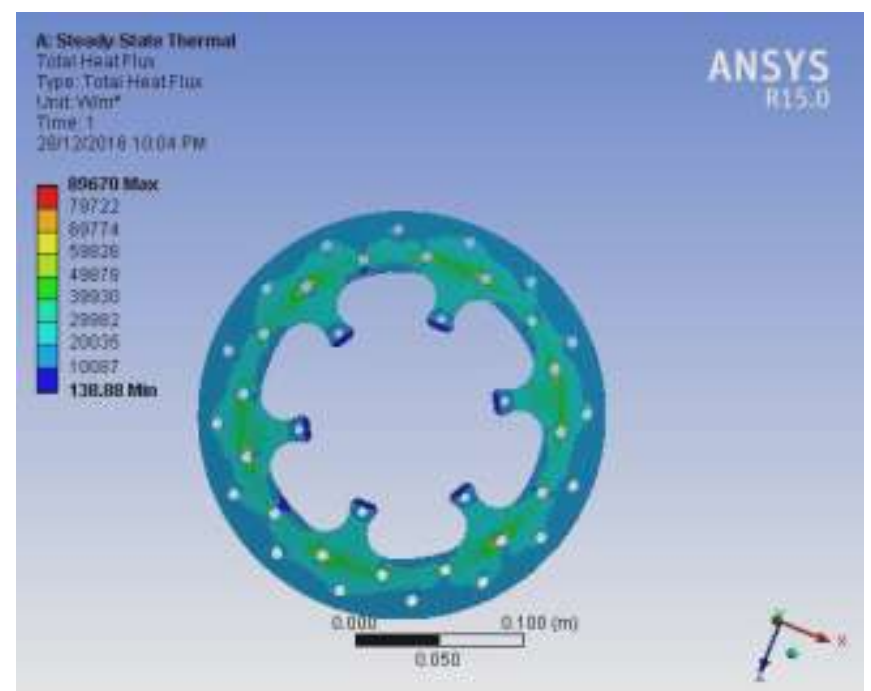

Fig-10: Total heat flux for profile I Aluminum.

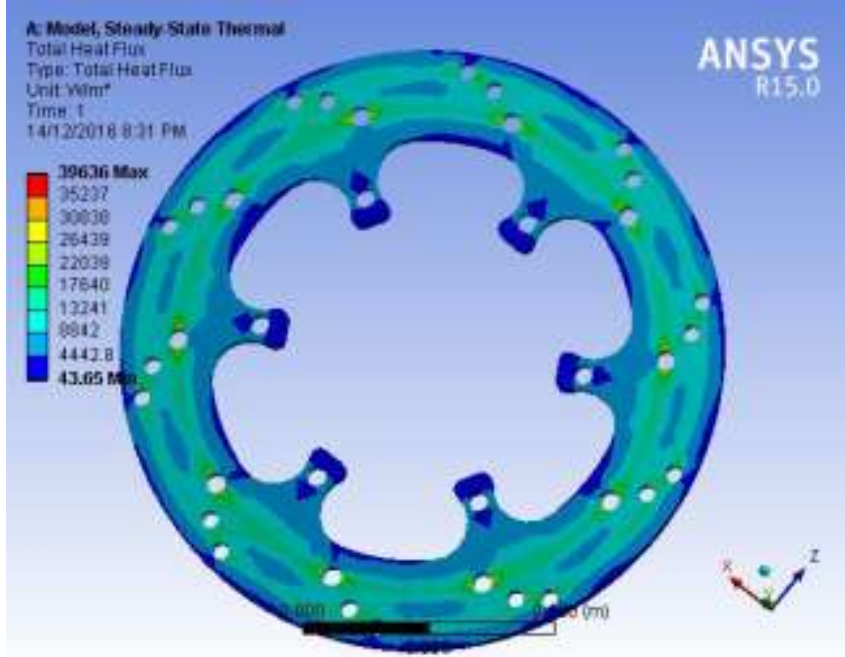

Fig-11: Total heat flux for profile II DB410.

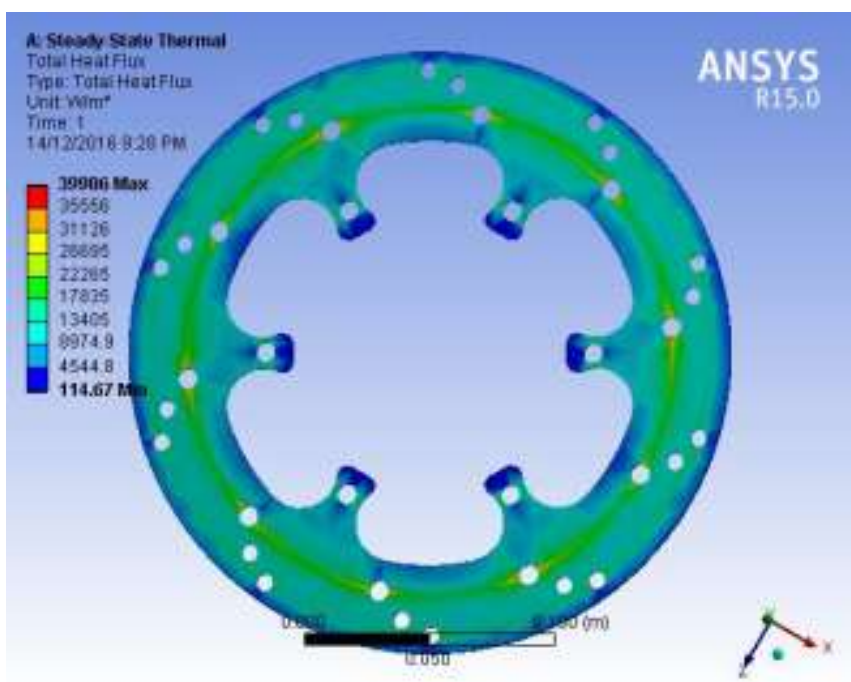

Fig-12: Total heat flux for profile II Cast iron.

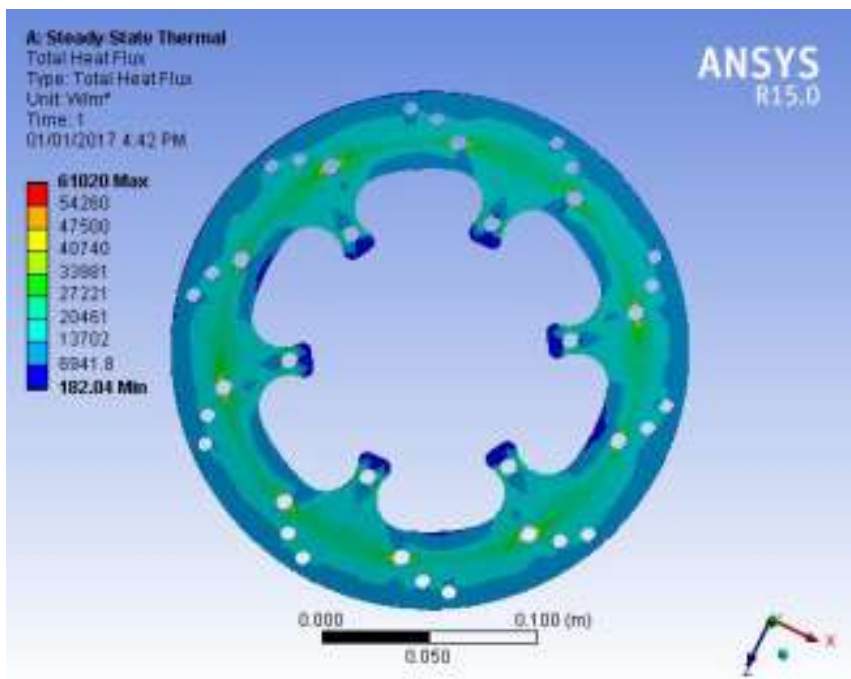

Fig-13: Total heat flux for profile II Aluminum. 


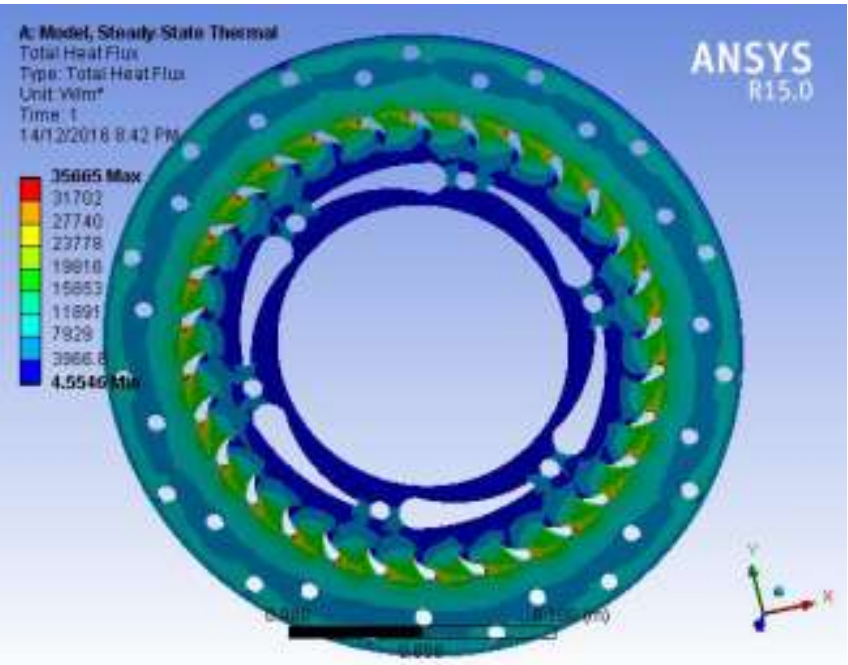

Fig-14: Total heat flux for profile III DB410.

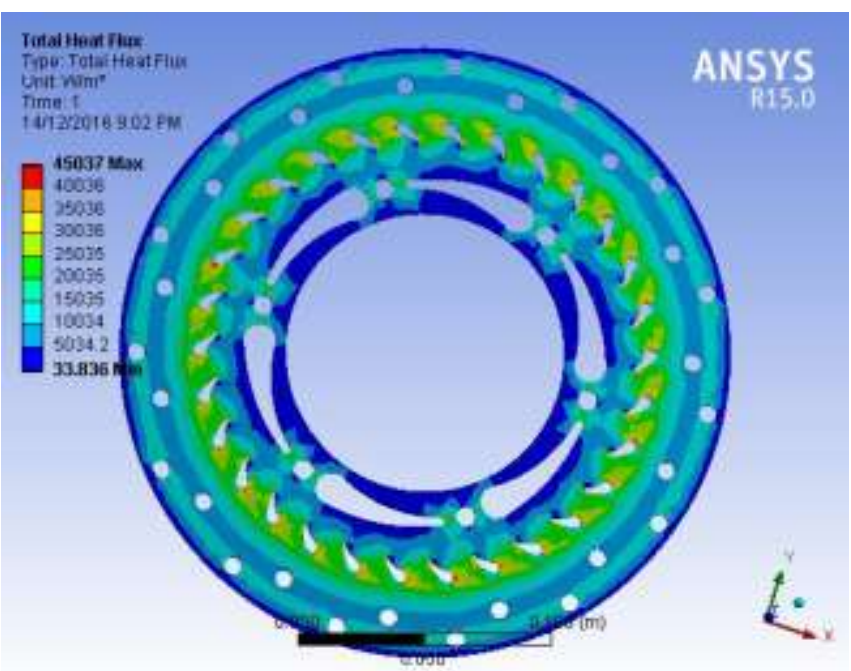

Fig-15: Total heat flux for profile III Cast iron.

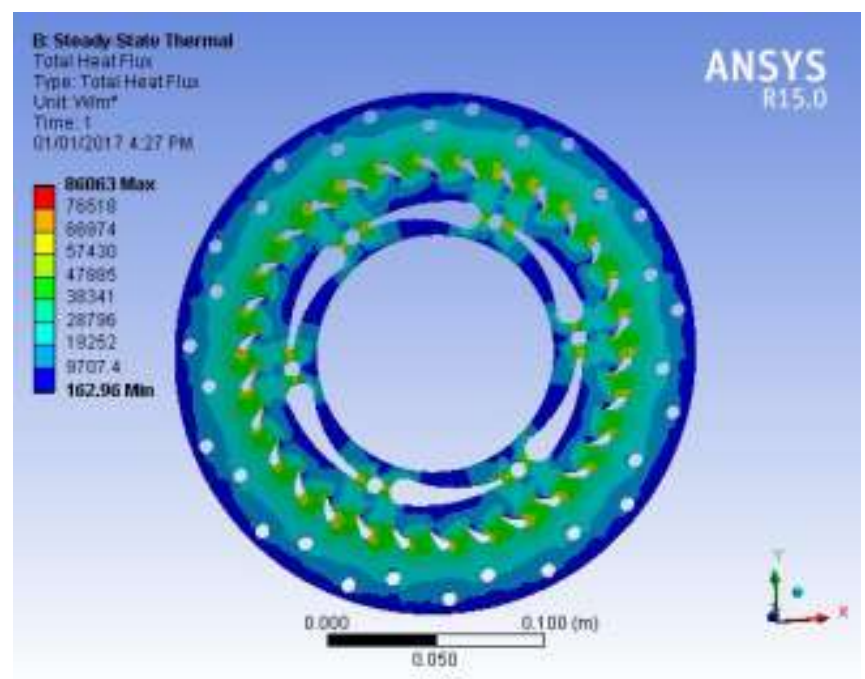

Fig-16: Total heat flux for profile III Aluminum.

The maximum temperature generated during the braking action is tabulated as shown below.
Table -1: Temperature Distribution for all profiles.

\begin{tabular}{|c|c|c|c|c|c|c|}
\hline \multirow{2}{*}{ Profile } & \multicolumn{2}{|c|}{ DB410 } & \multicolumn{2}{c|}{ Cast iron } & \multicolumn{2}{c|}{ Aluminum } \\
\cline { 2 - 7 } & Max & Min & Max & Min & Max & Min \\
\hline I & 79.27 & 31.00 & 60 & 40 & 65.40 & 29.54 \\
\hline II & 51.35 & 29.56 & 55 & 40 & 45.14 & 40.85 \\
\hline III & 54.06 & 23.52 & 35 & 28.26 & 41.60 & 21.80 \\
\hline
\end{tabular}

The heat flux distribution for all the profiles is also tabulated as shown below.

Table -1: Heat flux Distribution for all profiles.

\begin{tabular}{|c|c|c|}
\hline Material & Profile & Max.Value \\
\hline \multirow{4}{*}{ DB410 } & Profile I & 42407 \\
\cline { 2 - 3 } & Profile II & 39636 \\
\cline { 2 - 3 } & Profile III & 35665 \\
\hline \multirow{4}{*}{ Cast Iron } & Profile I & 47155 \\
\cline { 2 - 3 } & Profile II & 39986 \\
\cline { 2 - 3 } & Profile III & 45037 \\
\hline \multirow{3}{*}{ Aluminum } & Profile I & 89670 \\
\cline { 2 - 3 } & Profile II & 61020 \\
\cline { 2 - 3 } & Profile III & 86063 \\
\hline
\end{tabular}

\section{CONCLUSIONS}

By observing the values of heat flux distribution for the profiles, we come to conclusion that the heat flux dissipation is good for the aluminum but as the strength of aluminum is poor, we cannot use it for the manufacturing purpose.

Profiles made up of Cast iron also have better heat dissipation rate but the tendency of the cast iron is that it get corroded when comes in contact with water or moisture. Hence it is not suitable for production purpose.

DB410 materials have best heat dissipation and the life of the disc is considerably long. Also the disc made by DB410 can be heat treated. Hence DB410 material is selected for the manufacturing.

The heat dissipation rate is also depends on the orientation of the vent holes on the brake disc .so we can manufacture profile I with more numbers of holes using DB410 material.

\section{REFERENCES}

[1].C.Radhakrishnan, Yokeswaran.K, Naveen Kumar.M, Sarathkumar.Gopinath,Inbasekar."Design and optimization of ventilated disc brake for heat dissipation" International Journal of Innovative Science, Engineering \& Technology, Vol. 2 Issue 3, March 2015.

[2].G.Ranjith Kumar, S.Thriveni,M. Rajasekhar Reddy, Dr. G. HarinathGowd "Design Analysis \& Optimization of an Automotive Disc Brake"International Journal of Advanced Engineering Research and Science (IJAERS) [Vol-1, Issue3, Aug- 2014] 
[3].Vaibhav A. Ajmire and Sangeeta N. Bansode "Structure Optimization of Disc Brake"International Journal of Scientific Engineering and Applied Science (IJSEAS) Volume-1, Issue-7,October 2015

[4].Praveena S, Lava Kumar M, Kesavulu A "Modeling and Thermal Analysis of Disc Brake" Praveena S Int. Journal of Engineering Research and Applications Vol. 4, Issue 10(Part - 3), October 2014.

[5].Venkatramanan R, Kumaragurubaran SB, Vishnu Kumar C, Sivakumar S,Saravanan B. "Design and Analysis of Disc Brake Rotor"International Journal of Applied Engineering Research ,Volume 10, Number 19 (2015).

[6].Gnanesh P, Naresh C and Syed AltafHussain "finite element analysis of normal and Vented disc brake rotor.'International journal of mechanical engineering and robotics research, Vol. 3, No. 1, January 2014.

[7].HemrajNimhal, ChitranjanAgarwal, S. Jindal, M. A. Saloda "Thermal Analysis of Disc Brake using Ansys Software" International Journal of Advance Engineering and Research Development Volume 3, Issue 3, March -2016

[8].BaskaraSethupathi P, Muthuvel A, Prakash N., Stanly Wilson Louis "Numerical Analysis of a Rotor Disc for Optimization of the Disc Materials" Journal of Mechanical Engineering and Automation 2015.

[9].SubhasisSarkar (Dr.) Pravin P. Rathod A. J. Modi "Research Paper on Modeling and Simulation of Disc Brake to Analyse Temperature Distribution using FEA" IJSRD International Journal for Scientific Research \& Development| Vol. 2, Issue 03, 2014.

[10].A. Belhocine, C.-D. Cho, M. Nouby, Y. B.Y, A. R. Abu Bakar "Thermal analysis of both ventilated and full disc brake rotorswith frictional heat generation" Applied and Computational Mechanics 8 (2014) 5-24. 